\title{
Correction to: Containing pandemics through targeted testing of households
}

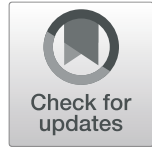

André Voigt ${ }^{1}$, Nikolay Martyushenko', Emil Karlsen', Martina Hall ${ }^{1}$, Kristen Nyhamar', Stig William Omholt² and Eivind Almaas ${ }^{1,3^{*}}$

\section{Correction to: BMC Infectious Diseases 21, 548 (2021) https://doi.org/10.1186/s12879-021-06256-8}

Following publication of the original article [1], it was noted that due to a typesetting error the figure legends were paired incorrectly.

The caption of Fig. 1 belongs to Fig. 2. And the caption of Fig. 2 belongs to Fig. 1.

The correct figures and captions have been included in this correction, and the original article has been corrected.

* Correspondence: eivind.almaas@ntnu.no

'Department of Biotechnology and Food Science, NTNU - Norwegian University of Science and Technology, Trondheim, Norway

${ }^{3}$ K.G. Jebsen Center for Genetic Epidemiology, NTNU - Norwegian University of Science and Technology, Trondheim, Norway

Full list of author information is available at the end of the article

(c) The Author(s). 2021 Open Access This article is licensed under a Creative Commons Attribution 4.0 International License, which permits use, sharing, adaptation, distribution and reproduction in any medium or format, as long as you give appropriate credit to the original author(s) and the source, provide a link to the Creative Commons licence, and indicate if changes were made. The images or other third party material in this article are included in the article's Creative Commons licence, unless indicated otherwise in a credit line to the material. If material is not included in the article's Creative Commons licence and your intended use is not permitted by statutory regulation or exceeds the permitted use, you will need to obtain permission directly from the copyright holder. To view a copy of this licence, visit http://creativecommons.org/licenses/by/4.0/. The Creative Commons Public Domain Dedication waiver (http://creativecommons.org/publicdomain/zero/1.0/) applies to the data made available in this article, unless otherwise stated in a credit line to the data. 

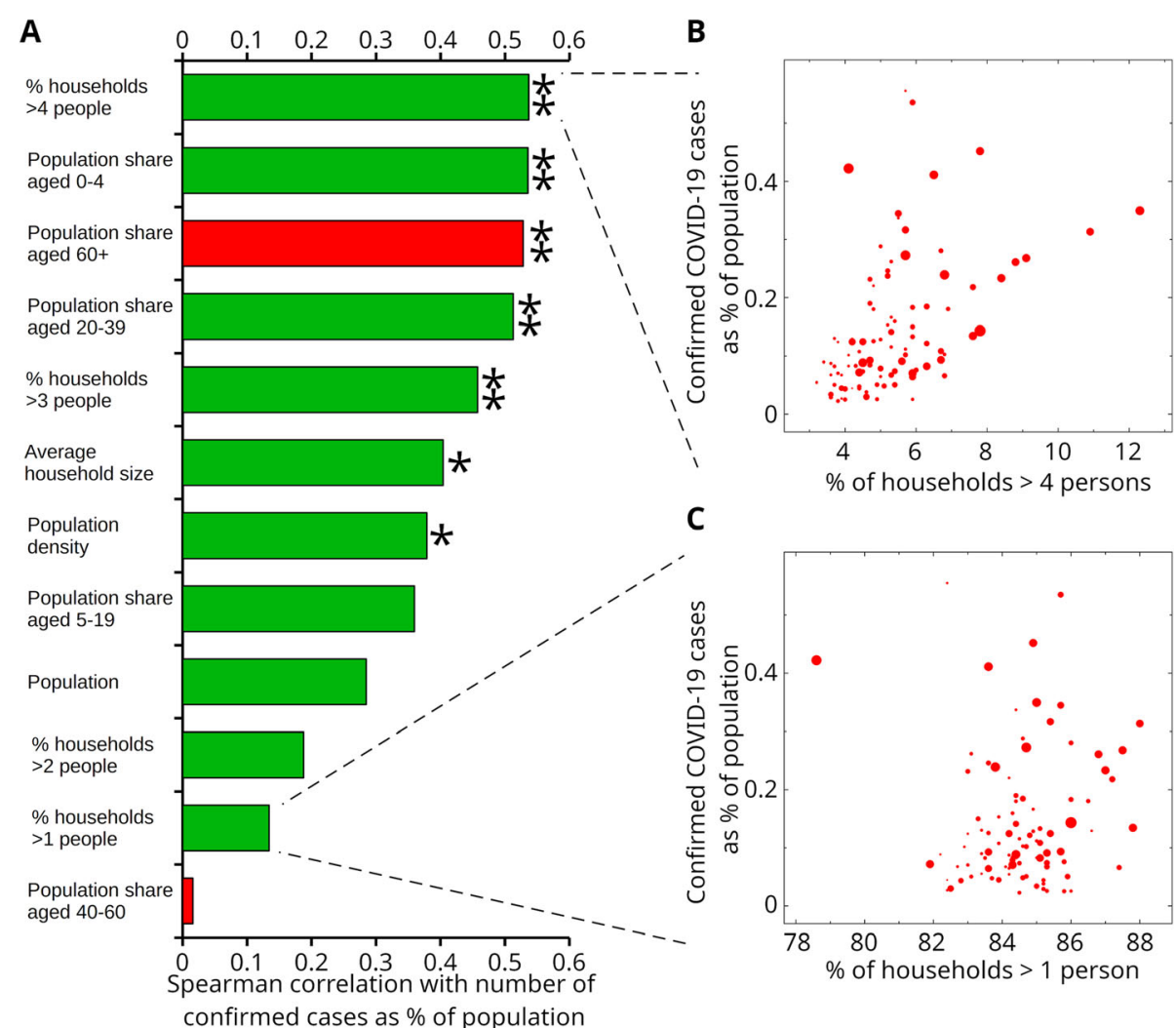

\section{C}

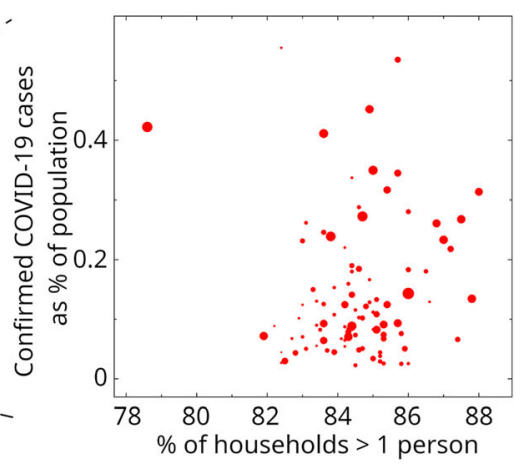

Fig. 1 Demographic parameters associated with COVID-19 spread in France. A Correlation histogram (positive, green; negative, red) shows larger household sizes significantly correlated with levels of COVID-19 hospitalizations. Single (double) star indicates Bonferroni-corrected significance $P<0.01$ $(P<0.001)$. Panels $\mathbf{B}$ and $\mathbf{C}$ show scatter plots of confirmed cases (as percentage of population) for the 96 departments of European France as function of the percentage of households larger than four persons and one, respectively. Size of markers is proportional to the population of each department 


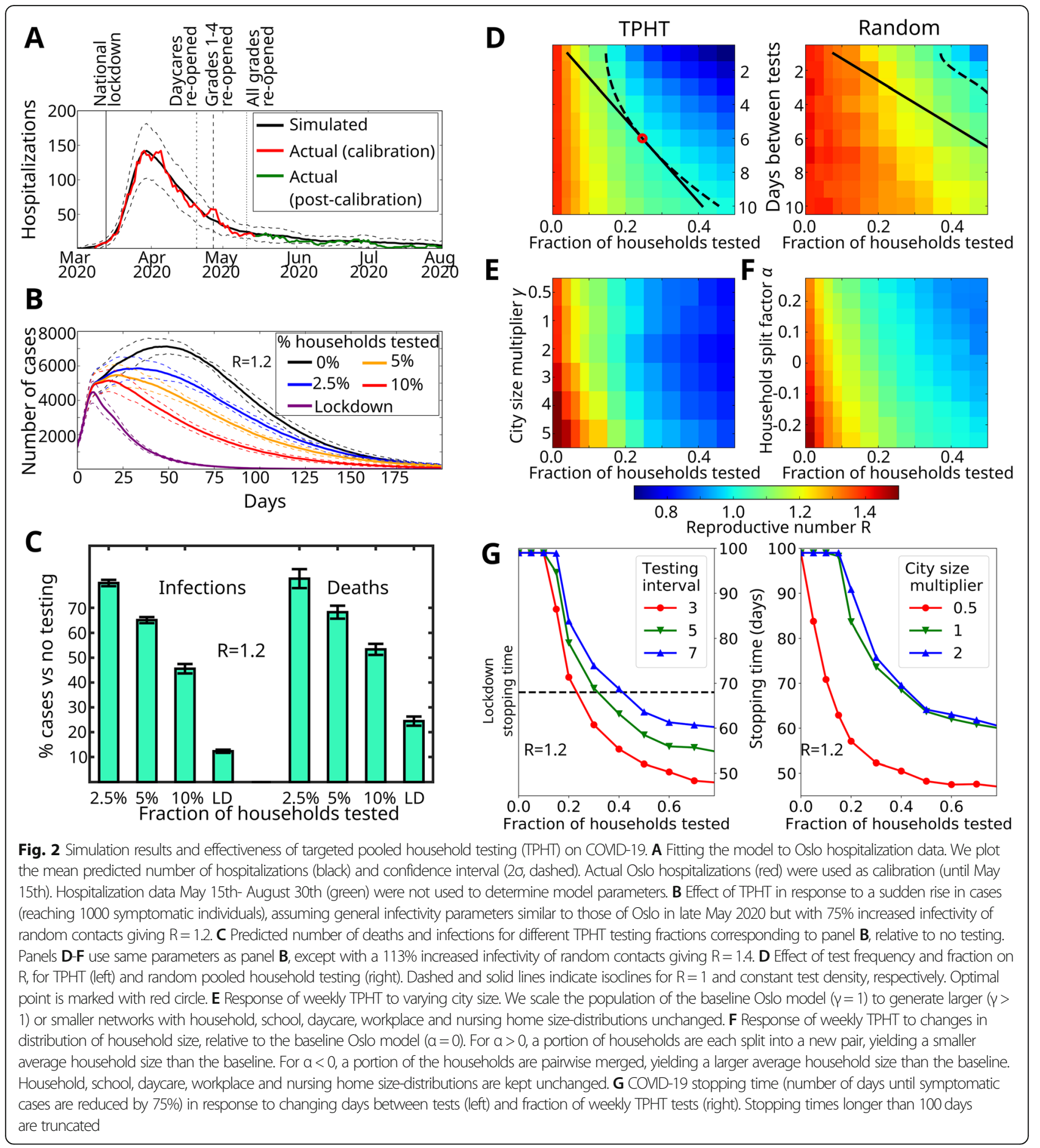

\section{Author details}

${ }^{1}$ Department of Biotechnology and Food Science, NTNU - Norwegian University of Science and Technology, Trondheim, Norway. ${ }^{2}$ Department of Circulation and Medical Imaging, NTNU - Norwegian University of Science and Technology, Trondheim, Norway. ${ }^{3}$ K.G. Jebsen Center for Genetic Epidemiology, NTNU - Norwegian University of Science and Technology, Trondheim, Norway.
Published online: 06 July 2021

\section{Reference}

1. Voigt A. et al., Containing pandemics through targeted testing of households. BMC Infect Dis. 2021;21:548. https://doi.org/10.1186/s12879021-06256-8. 